\title{
O Impacto da Ausência de Vedamento Coronal na Infiltração
}

\section{Endodôntica: Revisão Sistemática}

\section{The Impact of Coronal Sealing's Absence on Endodontic Infiltration: Systematic Review}

\author{
Edwaldo de Souza Barbosa Júnior ${ }^{1}$ \\ Falyne Pinheiro de Oliveira ${ }^{2}$ \\ Laura Marcelly Teixeira Gomes ${ }^{3}$ \\ Danilo Cangussu Mendes 4 \\ Renata Francine Rodrigues Lima 5 \\ Soraya Mameluque ${ }^{6}$
}

Resumo: A restauração coronária se relaciona ao sucesso e bom prognóstico do tratamento endodôntico, pois ainda que os canais radiculares sejam obturados em condições ideais, a microinfiltração estará presente caso não haja selamento coronal, pois os microrganismos da cavidade bucal penetrarão através dos canais radiculares preenchidos, podendo atingir os tecidos periapicais, provocando infecções. Objetivo: Apresentar diferentes estudos e conclusões sobre a infiltração endodôntica, buscando responder qual o impacto da ausência de vedamento coronal na infiltração coronária em dentes tratados endodonticamente. Método: Foi realizada uma revisão literária sistemática seguindo etapas preconizadas pelo Joanna Briggs Institute, utilizando os descritores e sinônimos obtidos pelo DeCS e MeSH:

\footnotetext{
1 Mestre em Dentística (São Leopoldo Mandic). Professor da Universidade Estadual de Montes Claros (Unimontes). Minas Gerais. Brasil. $₫$ edwaldobarbosajunior@gmail.com (iD https://orcid.org/0000-00027833-0654

${ }^{2}$ Graduanda em Odontologia pela Universidade Estadual de Montes Claros (Unimontes). Minas Gerais. Brasil. $₫$ falyne.pinheiro@gmail.com (i) https://orcid.org/0000-0003-1658-7945

${ }^{3}$ Graduanda em Odontologia pela Universidade Estadual de Montes Claros (Unimontes). Minas Gerais. Brasil. $\triangle \underline{\text { laura.marcelly98@gmail.com (i) https://orcid.org/0000-0001-8968-0636 }}$

${ }^{4}$ Pós-doutor em Ciências da Saúde (Unimontes). Professor da Universidade Estadual de Montes Claros (Unimontes). Minas Gerais. Brasil. $\triangle$ danilocangussuodonto@yahoo.com.br (iD https://orcid.org/0000-0003$\underline{4766-0009}$

${ }^{5}$ Doutora em Ciências da Saúde (Unimontes). Professora da Universidade Estadual de Montes Claros (Unimontes). Minas Gerais. Brasil. $\triangle$ renatafrancine@gmail.com (iD https://orcid.org/0000-0002-7393-0415

${ }^{6}$ Doutora em Clínica Restauradora (FORP-USP). Professora da Universidade Estadual de Montes Claros (Unimontes). Minas Gerais. Brasil. $₫ \underline{\text { soraya.ferreira@unimontes.br }}$ (D) https://orcid.org/0000-0001-5711$\underline{9473}$
}

$\begin{array}{cccc}\text { Recebido em } & \text { Correções em } & \text { Aceito em } & \text { Publicado em } \\ 23 / 07 / 2020 & 01 / 11 / 2020 & 24 / 11 / 2020 & 31 / 12 / 2020\end{array}$


Root Canal Filling; Dental Restoration Failure; Dental Infiltration, combinados entre si para buscas de artigos científicos entre 2015 e 2020, através da plataforma da Biblioteca Virtual em Saúde (BVS). Resultados: Dos 86 artigos encontrados, 37 foram selecionados e destes, 09 excluídos por duplicidade. Dos 28 restantes, foram escolhidos 06 (cinco em inglês e um em espanhol), os quais abordavam o tema proposto. Os artigos selecionados foram organizados e tabulados para extração de dados conforme informações relevantes para solução da pergunta norteadora. Conclusão: É fundamental o tratamento restaurador adequado e de qualidade, com materiais provisórios e definitivos, para que assim possa ser fornecida longevidade aos tratamentos endodônticos.

Palavras-chave: Obturação do Canal Radicular. Falha de Restauração Dentária. Infiltração Dentária.

\begin{abstract}
Coronary restoration is related to the success and good prognosis of endodontic treatment, because even though the root canals are filled under ideal conditions, microleakage will be present if there is no coronal seal, as the microorganisms of the oral cavity will penetrate through the filled root canals reach the periapical tissues, causing infections. Objective: To present different studies and conclusions about endodontic infiltration, seeking to answer what is the impact of the absence of a coronal seal on coronary infiltration in endodontically treated teeth. Method: A systematic literary review was carried out following steps recommended by the Joanna Briggs Institute, using the descriptors and synonyms obtained by DeCS and MeSH: Root Canal Filling; Dental Restoration Failure; Dental Infiltration, combined with each other to search for scientific articles between 2015 and 2020, through the Virtual Health Library (BVS) platform. Results: Of the 86 articles found, 37 were selected and of these, 9 were excluded due to duplication. Of the remaining 28, 06 (five in English and one in Spanish) were chosen, which addressed the proposed theme. The selected articles were organized and tabulated for data extraction according to relevant information for solving the guiding question. Conclusion: Adequate and quality restorative treatment with provisional and definitive materials is essential, so that longevity can be provided for endodontic treatments.
\end{abstract}

Keywords: Root Canal Filling. Dental Restoration Failure. Dental Infiltration. 


\section{INTRODUÇÃO}

O tratamento endodôntico consiste na eliminação do tecido pulpar contaminado, no cuidado da área tratada para que não ocorra infecção ou reinfecção e visa impedir que aconteça, através da saliva, a penetração bacteriana e de endotoxinas, por meio do vedamento da luz dos canais. A microinfiltração de microrganismos da cavidade bucal através dos canais radiculares preenchidos pode atingir os tecidos periapicais, provocando infecções. Assim sendo, o prognóstico do tratamento endodôntico está intimamente relacionado à qualidade do preenchimento da raiz, bem como do selamento coronário ${ }^{1 ; 2 ; 3}$.

A fim de se evitar reinfecções, podem ser utilizados materiais obturadores intracanais e materiais restauradores coronários. As restaurações temporárias atuam como selamento provisório e devem impedir a entrada de microrganismos, fluidos e matéria orgânica oriundos da cavidade bucal para os canais radiculares durante o período de tratamento, além de possuir função terapêutica por meio do impedimento da perda de medicamentos inseridos nas raízes ${ }^{4 ;}$. A restauração definitiva, por sua vez, além de apresentar características como anatomia e estética favoráveis, deve realizar principalmente o vedamento marginal dos dentes, atuando como barreira permanente contra a infiltração da microflora bucal ${ }^{6}$.

A restauração coronária está intimamente ligada ao sucesso e bom prognóstico do tratamento endodôntico. Assim, quando o selamento se encontra defeituoso, torna-se possível a introdução de bactérias e endotoxinas na porção coronária, podendo atingir a região radicular e apical, proporcionando falha na terapia ${ }^{7 ; 8}$. Em um estudo de Ray e Trope ${ }^{3}$, é mostrado que a condição restauradora tem associação significativamente maior com danos apicais do que com o insucesso do tratamento endodôntico em si.

Os fatores causadores da microinfiltração podem ser diversos, podendo estar relacionados com os condutos radiculares devido à técnica de preparação, à qualidade da obturação radicular ou à interface cimento-dente. No aspecto restaurador, a microinfiltração também ocorre de várias formas, desde que exista o desprendimento do material, que pode acontecer por deterioração que exponha a superfície de obturação endodôntica, fraturas, perdas, espessura inadequada na restauração temporária ou atraso na colocação da restauração permanente, o que anula sua efetividade e permite a penetração de bactérias nos tecidos periapicais ${ }^{7 ; 9 ; 10}$. 
Ainda que os canais radiculares sejam obturados em condições ideais, a microinfiltração estará presente caso não haja selamento coronal ${ }^{3 ; 11}$. Os canais radiculares tratados endodonticamente, quando expostos ao meio bucal através da microinfiltração coronal, podem ser recontaminados, ao ponto de que o retratamento seja necessário, indicando falha do tratamento endodôntico ${ }^{9 ; 10}$. Dessa forma, a qualidade da restauração coronal é mais importante a longo prazo no prognóstico do dente do que o tratamento endodôntico em $\mathrm{si}^{2}$.

Esta revisão de literatura objetivou apresentar 06 diferentes estudos e conclusões a respeito de infiltração endodôntica, buscando responder a seguinte pergunta: Qual impacto da ausência de vedamento coronal na infiltração coronária em dentes tratados endodonticamente?

\section{MÉTODO}

Trata-se de uma revisão sistemática da literatura, na qual foram reunidos e sintetizados os achados de estudos a respeito de restaurações com ausência de vedamento coronal e seu impacto sobre a infiltração coronária em dentes tratados endodonticamente. Para tanto, realizaram-se etapas preconizadas pelo Joanna Briggs Institute ${ }^{12}$, que consistem na identificação do tema e seleção da questão de pesquisa; no estabelecimento dos critérios de inclusão e exclusão; na identificação dos estudos pré-selecionados e selecionados; na categorização dos estudos selecionados; na análise e interpretação dos resultados e na apresentação da revisão/síntese do conhecimento.

Para a identificação do tema e construção da pergunta de pesquisa, foi utilizada a estratégia PCC, que representa um acrônimo para Population, Concept e Context $^{12}$. Dessa forma, definiu-se: P- dentes tratados endodonticamente; C- impacto da ausência de vedamento coronal e C- na infiltração coronária. A questão norteadora definida foi: Qual impacto da ausência de vedamento coronal na infiltração coronária em dentes tratados endodonticamente?

A definição dos descritores a serem pesquisados ocorreu conforme busca pelos Descritores em Ciências da Saúde (DeCS) na Biblioteca Virtual em Saúde (BVS) e Medical Subject Headings (MeSH) no National Center for Biotechnology Information (NCBI). Foram definidos 03 grupos de descritores, cada um contendo 03 sinônimos em inglês, sendo estes: 
1 - Root canal obturation; endodontic obturation; canal obturation, root;

2 - Dental restoration failure; restoration failure, dental; restoration failures, dental;

3 -Dental leakage; dental leakages; leakages, dental.

Realizou-se a coleta de dados no mês de maio de 2020 nas bases de dados MEDLINE E LILACS através da plataforma da BVS, na qual houve a combinação dos descritores pré-definidos através do uso dos booleanos $O R$ e $A N D$, de modo que os grupos fossem combinados entre si.

Os seguintes filtros foram empregados para a pesquisa: texto completo disponível, estar nas bases de dados MEDLINE e LILACS, apresentar a infiltração dentária como assunto principal, ser escrito nos idiomas português, espanhol e inglês, textos publicados nos últimos 05 anos e o tipo de documento (artigo).

Os critérios de inclusão adotados consistiram em artigos que abordassem o tema proposto, independente de sua categoria (original, revisão de literatura, reflexão e atualização ou relato de experiência), e que contivessem no título ou no resumo os descritores já mencionados. O critério de exclusão foi: artigos não relacionados ao tema proposto neste trabalho.

\section{RESULTADOS}

As publicações identificadas pelas buscas no banco de dados a partir dos descritores previamente estabelecidos resultaram inicialmente em 86 artigos científicos. A partir da leitura crítica, segundo títulos e resumos, 37 relatos foram selecionados. Destes, 09 foram excluídos após identificação por duplicidade. Restaram 28 artigos avaliados através da leitura completa, por pelo menos um revisor, selecionados conforme os critérios de elegibilidade. 06 estudos foram escolhidos qualitativamente e incluídos para a amostra final desta revisão, sendo 05 da língua inglesa e 01 da língua espanhola. Os processos de seleção e análise das publicações, representados na Figura 1, foram realizados através da orientação e do fluxograma PRISMA (Principais Itens para Relatar Revisões Sistemáticas e Metaanálise $)^{13}$. 
Figura 1: Fluxograma que descreve o processo de seleção dos artigos científicos a partir de busca sistematizada.

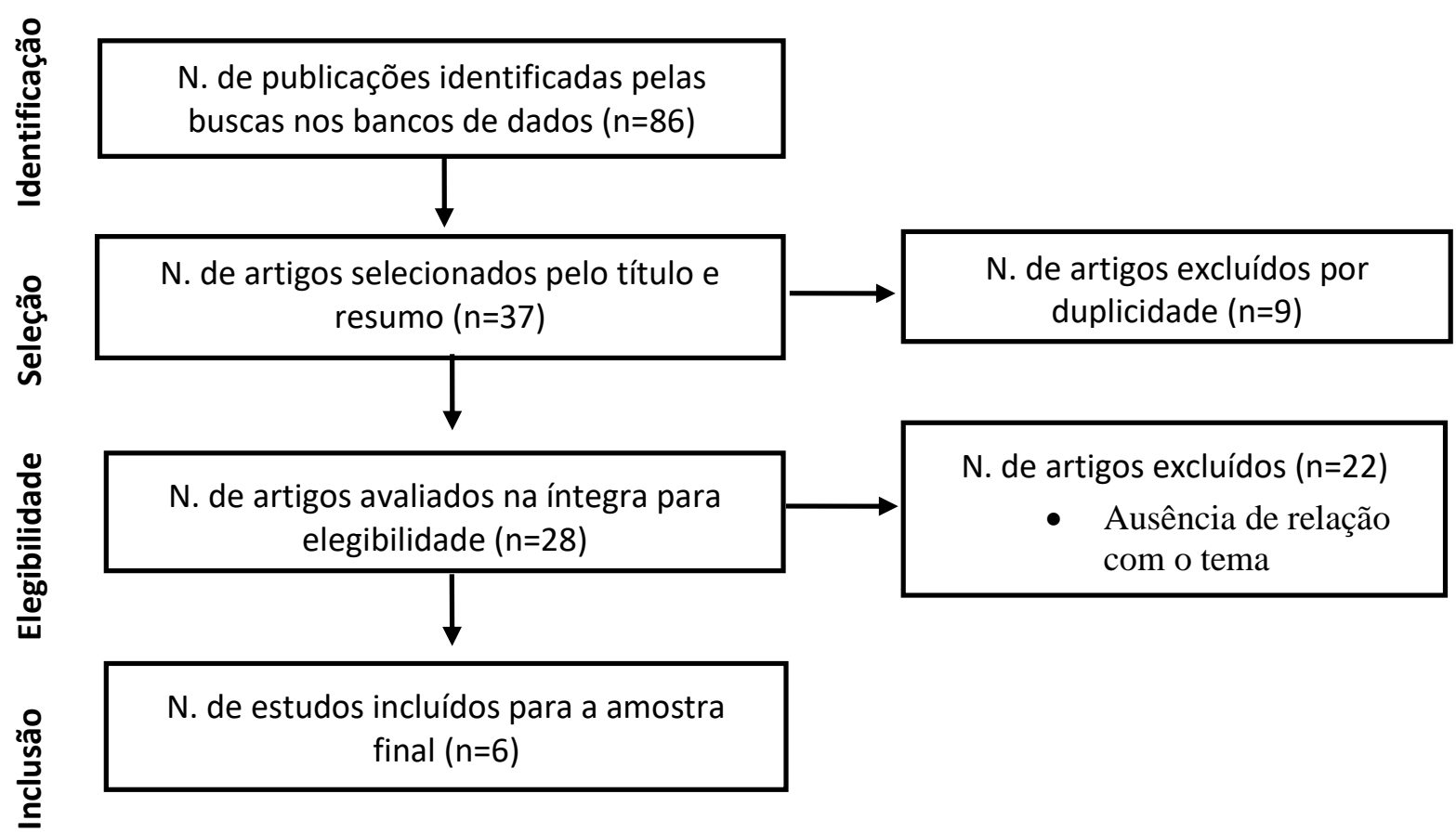

Os estudos incluídos para a amostra final (Quadro 1) resultaram em artigos de metodologias heterogêneas sobre o assunto, sendo 04 estudos laboratoriais e 02 revisões sistemáticas. As publicações foram selecionadas dos periódicos International Journal of Prosthodontic, European Archives of Paediatric Dentistry, Journal of Prosthodontics, Minerva Stomatologica e Revista Cubana de Estomatologia. Os relatos foram organizados e tabulados para extração de dados conforme informações relevantes para solução da pergunta norteadora. Os dados registrados foram: I. Autor e o ano de publicação do trabalho; II. Delineamento do estudo; III. Tipo de material restaurador abordado na pesquisa; IV. Tamanho da amostra avaliada e V. Resultados do estudo e implicações sobre a infiltração dentária. 
Quadro 1: Descrição dos artigos incluídos nesta revisão sistemática segundo pergunta norteadora do estudo.

\begin{tabular}{|c|c|c|c|c|}
\hline $\begin{array}{l}\begin{array}{c}\text { Autor/Ano } \\
\text { de } \\
\text { publicação }\end{array} \\
\text { pula }\end{array}$ & $\begin{array}{l}\text { Delineamento } \\
\text { do estudo }\end{array}$ & $\begin{array}{c}\text { Material } \\
\text { restaurador } \\
\text { abordado }\end{array}$ & $\begin{array}{l}\text { Tamanho } \\
\text { da amostra }\end{array}$ & Resultados \\
\hline $\begin{array}{l}\text { Labrada M, } \\
\text { Maya Cerón } \\
\text { C. } / 2015\end{array}$ & $\begin{array}{l}\text { Revisão } \\
\text { sistemática }\end{array}$ & $\begin{array}{l}\text { Temporário/ } \\
\text { definitivo }\end{array}$ & 53 artigos & $\begin{array}{l}\text { A prevenção da } \\
\text { microinfiltração dentária } \\
\text { tem-se com utilização de } \\
\text { instrumentos e materiais } \\
\text { estéreis no conduto } \\
\text { radicular, além do uso de } \\
\text { material temporário } \\
\text { durante o tratamento } \\
\text { endodôntico e reabilitação } \\
\text { definitiva do dente, no } \\
\text { menor intervalo de tempo } \\
\text { para evitar a ausência do } \\
\text { vedamento coronal. }\end{array}$ \\
\hline
\end{tabular}

\begin{tabular}{|c|c|c|c|c|}
\hline $\begin{array}{l}\text { Lee KS, et } \\
\text { al. } / 2015\end{array}$ & $\begin{array}{l}\text { Experimento } \\
\text { laboratorial (in } \\
\text { vitro) }\end{array}$ & Definitivo & $\begin{array}{l}70 \text { pré- } \\
\text { molares } \\
\text { humanos } \\
\text { unirradicula } \\
\text { res }\end{array}$ & $\begin{array}{l}\text { Diferentes materiais de } \\
\text { vedação } \\
\text { permitiram infiltração de } \\
\text { corante, representando } \\
\text { possível falha na vedação } \\
\text { de restauração coronária } \\
\text { durante ou após o } \\
\text { tratamento endodôntico. }\end{array}$ \\
\hline
\end{tabular}

Jafari F. et Revisão Temporário/ Não $\quad$ Os diferentes estudos sobre al./2017 sistemática definitivo informado microinfiltração dentária são essenciais para entendimento clínico, sendo recomendado análises a partir de testes da reatividade à glicose e avaliação da atividade antimicrobiana dos materiais testados, já que estes têm maior confiabilidade quanto ao vazamento bacteriano.

\begin{tabular}{|c|c|c|c|c|}
\hline $\begin{array}{l}\text { Al-Madi } \\
\mathrm{EM}, \text { et al. } \\
\text { /2018 }\end{array}$ & $\begin{array}{l}\text { Experimento } \\
\text { laboratorial (in } \\
\text { vitro) }\end{array}$ & Definitivo & $\begin{array}{l}48 \text { dentes } \\
\text { unirradicula } \\
\text { res entre }\end{array}$ & $\begin{array}{l}\text { Em casos de lacunas na } \\
\text { extremidade apical e } \\
\text { coronal entre o núcleo e o }\end{array}$ \\
\hline
\end{tabular}


caninos e material obturador, a pré-molares. microinfiltração aumenta significativamente, mesmo com a presença de cimento entre eles, pois não é possível ter vedamento completo.

\begin{tabular}{|c|c|c|c|c|}
\hline $\begin{array}{l}\text { Mohajerfar } \\
\text { M. et al. } \\
/ 2018\end{array}$ & $\begin{array}{l}\text { Experimento } \\
\text { laboratorial (in } \\
\text { vitro) }\end{array}$ & Definitivo & $\begin{array}{l}32 \text { caninos e } \\
\text { pré-molares } \\
\text { unirradicula } \\
\text { res. }\end{array}$ & $\begin{array}{lr}\text { A microinfiltração coronal } \\
\text { é possível de ocorrer ainda } \\
\text { que o dente esteja com pino } \\
\text { intrarradicular. } \\
\text { estudo, são } & \text { relatados } \\
\text { diversos } & \text { agentes } \\
\text { cimentantes com diferentes } \\
\text { graus de penetração } \\
\text { bacteriana. }\end{array}$ \\
\hline $\begin{array}{l}\text { Babu NSV. } \\
\text { et al. } / 2019\end{array}$ & $\begin{array}{l}\text { Experimento } \\
\text { laboratorial (in } \\
\text { vitro) }\end{array}$ & Temporário & $\begin{array}{l}60 \text { primeiros } \\
\text { molares } \\
\text { humanos }\end{array}$ & $\begin{array}{l}\text { O estudo apontou que } \\
\text { determinado material } \\
\text { restaurador temporário, } \\
\text { contendo nano-prata, } \\
\text { possuía melhor vedação e } \\
\text { seu uso é recomendado } \\
\text { entre sessões de tratamento } \\
\text { endodôntico em dentes } \\
\text { decíduos, para obter melhor } \\
\text { vedamento coronal. }\end{array}$ \\
\hline
\end{tabular}

\section{DISCUSSÃO}

Para se verificar o quão adequado é a vedação proporcionada por determinados materiais, estudos in vitro podem ser realizados através de metodologias diversas, como o uso de corantes, isótopos radioativos, bolhas de ar, microorganismos, filtração por glicose, método eletroquímico e análise por microscopia eletrônica ${ }^{7 ; 14 ; 15}$. O uso de corantes é um método eficiente, por apresentar baixo peso molecular e consequente infiltração análoga ao ácido butírico, que é um produto metabólico bacteriano ${ }^{15}$.

A fim de se obter sucesso no tratamento endodôntico, o vedamento coronário proporcionado pelos materiais restauradores, tanto provisórios, quanto definitivos, é de suma importância. Por isso, diferentes produtos foram testados quanto à habilidade de vedação do selamento coronal. Entretanto, por apresentarem diferentes metodologias, a comparação 
fidedigna é comprometida. Apesar de divergências, o uso de barreira intra-orifício, por exemplo, é caracterizado em vários estudos como agente capaz de dificultar a microinfiltração. Apesar disso, o único consenso quanto ao uso se refere à espessura, que deve ser de 3 a $4 \mathrm{~mm}^{14}$.

No estudo de Babu et $a l .{ }^{4}$, foi analisada a microinfiltração gerada pelo uso de quatro materiais restauradores temporários em dentes decíduos e comprovou-se que houve infiltração em todos os materiais. O IRM, produto à base de óxido de zinco-eugenol (OZE), mostrou baixa capacidade de vedação, o que pode ser justificado por sua instabilidade dimensional, devido ao estresse térmico da termociclagem, além do fato de que a mistura heterogênea, gerada em decorrência da indispensabilidade do preparo manual, provoca alterações de volume no material, resultando em contração. O Cavit $\mathrm{G}$, produto à base de sulfato de cálcio, não obteve diferenças estatisticamente significantes em relação aos demais materiais, mas mostrou concordância com estudos realizados previamente ao apresentar menor microinfiltração que o IRM, pois tem boa capacidade de vedação marginal, que se deve ao fato de ser um material higroscópico com alto coeficiente de expansão linear, além de possuir características antimicrobianas e de a preparação ser pronta para o uso, sem necessidade de manipulação. O Orafil-G, produto à base de óxido de zinco e sulfato de zinco, reforçado com resina EVA (acetato de vinil etileno), também apresentou microinfiltração, mas foi menor que a do IRM, uma vez que sua vedação marginal é boa, devido à sua presa higroscópica, além de possuir as vantagens de não ser irritante, já que não conta com o eugenol em sua formulação, possui propriedades bactericidas e a mistura pré-preparada conta com o agradável sabor de menta. Por fim, o Dia-Temp, material que contém nanoprata, apresenta alta elasticidade e dureza superficial e foi a substância com menor índice de microinfiltração, além de demonstrar boa aderência e a vantajosa capacidade de ser completamente removido de uma única vez, sem uso de brocas e sem deixar partículas.

Em contraste a esses resultados apresentados pelo uso dos materiais em dentes decíduos, pesquisas realizadas na dentição permanente apontaram as preparações à base de óxido de zinco como menos favoráveis à infiltração quando comparadas a materiais à base de sulfato de cálcio, fato que se dá em decorrência da menor solubilidade e da maior força compressiva demonstradas pelos materiais de $\mathrm{OZE}^{4}$.

Lee, et al. ${ }^{15}$ compararam a competência de vedação coronal através de barreiras intra-orifício de materiais de vedação à base de água, derivados do Agregado de Trióxido Mineral (MTA) (ProRoot WMTA, Angelus White e EndoCem Zr) e outros materiais 
restauradores (LuxaCore, Fuji II LC e Elite). Observou-se que as preparações de MTA apresentaram maior capacidade de vedação, provavelmente por sua propriedade hidrofílica e leve tendência de expansão, sendo que, destas, o ProRoot WMTA tinha a melhor capacidade de vedação e o EndoCem $\mathrm{Zr}$ a menor, quando comparados ao Angelus White. O LuxaCore (resina composta) e o Angelus White não apresentaram diferenças significativas quanto à infiltração, pois a eficácia de vedação do primeiro possivelmente foi relacionada ao uso de agente de ligação à dentina. O Fuji II LC, um Ionômero de Vidro Modificado por Resina, obteve a segunda pior quantidade de vazamento, o que pode ser explicado pela dificuldade de se conseguir uma mistura uniforme de seus componentes pó e líquido, além de que, em dentes tratados endodonticamente, a probabilidade de absorção de água é limitada, o que pode provocar contração dos materiais dessa classe, resultando em grande vazamento. O Elite, um cimento de policarboxilato de zinco, apresentou a maior quantidade de microinfiltração, fato explicado por sua baixa resistência de união. Apesar de possuir vantagens como dados clínicos mais longos, conveniência de uso e baixo custo, trata-se de um material desvantajoso por ser quebradiço, apresentar falta de adesão e solubilidade na boca, além de que o aumento da quantidade de água resulta na redução da resistência à compressão e à tração, não sendo recomendado o uso de Elite como barreira intra-orifício.

Quando é cogitada a colocação de um núcleo metálico fundido após o tratamento endodôntico, deve-se estudar a união entre os materiais derivados do MTA como barreira intra-orifício e a resina de cimentação do núcleo. Os resultados são controversos quanto à colaboração de variados sistemas adesivos para a resistência de união entre materiais derivados de MTA e compósitos resinosos usados para cimentação de núcleo, pois o AdheSE OneF (sistema de autocondicionamento em uma etapa) já foi apontado como o melhor agente de união, mas os sistemas adesivos de dois passos também já foram pontuados como causadores de maior resistência adesiva. Por apresentar o menor valor de microinfiltração, o ProRoot WMTA pode ser usado como eficiente barreira intra-orifício no dente com tratamento endodôntico quando se intenciona colocar um núcleo, uma vez que os resultados deste estudo mostraram que os materiais de MTA podem ser utilizados como uma barreira coronal.

O uso de núcleos metálicos fundidos afeta a microinfiltração de acordo com suas características, seja a dureza, a retenção ou a folga marginal. Por isso, é justo dizer que um tratamento endodôntico eficaz, associado a uma cimentação apropriada, pode resultar em maior dificuldade de invasão bacteriana. Assim, a vedação está mais relacionada à 
cimentação do que às propriedades do núcleo. Logo, a escolha do material cimentante mais adequado, de acordo com suas singularidades, é relevante no que diz respeito à prevenção da microinfiltração ${ }^{7 ; 8}$.

O estudo de Mohajerfar, et al. ${ }^{8}$ buscou estabelecer o melhor agente cimentante para núcleos metálico-fundidos através da comparação entre GI, Panavia F 2.0, Speed CEM e fosfato de zinco (ZP). Todos os materiais sofreram microinfiltração, sendo que o ZP mostrou os piores resultados, o que pode ser justificado pela alta solubilidade e pela ausência de ligação química, uma vez que sua consistência cremosa dificulta o contato com as fibras colágenas da dentina expostas pela desmineralização condicionadora, provocando uma redução progressiva na qualidade da união entre material/dente e o desenvolvimento de lacunas que facilitam a microinfiltração. O Speed CEM apresentou menor taxa de infiltração relativo apenas ao ZP, pois apesar de sua aplicação ser em etapa única, possibilita a invasão de monômeros ácidos na dentina e a criação de ligação entre eles. Esses monômeros são fracos e não permitem remoção completa da camada de esfregaço. A viscosidade desse produto e o rápido contato com o dente antes da polimerização podem facilitar a microinfiltração, assim como os distintos coeficientes de dilatação térmica do material e do dente/metal, que provocam tensões em suas áreas de contato, além do fato de que o produto é hidrolisado na interface durante a termociclagem, a qual simula condições clínicas. Já o grupo GI obteve segundo melhor resultado, que talvez seja devido ao não uso de condicionamento ácido para remoção da camada de esfregaço e à manipulação do produto, resultando em porosidades que afetaram a ligação intermolecular entre o dente e o material. Ademais, a termociclagem pode ter ocasionado estresse ao alterar o volume da amostra, gerando microfissuras e consequentes tensões maiores que a resistência do produto. Por fim, o Panavia F 2.0 demonstrou melhor habilidade seladora coronal, justificada por sua composição oleaginosa, que o torna insolúvel aos fluidos bucais, e pela sua aplicação em dois passos, utilizando um primer inicialmente, que origina uma camada híbrida impermeável e resistente a ácidos.

Apesar de usar técnicas como a termociclagem a fim de simular condições clínicas aos dentes, uma das limitações do estudo acima foi não ter reproduzido todas elas, como as condições de carga cíclica, além de ter sido realizada uma amostra restrita, que não continha tipos diversos de dentes. Ademais, ocorreu uma dificuldade em padronizar as preparações e cimentações e a proporção do GI pó e líquido, o que não permite exemplares similares para uso ${ }^{8}$. 
No estudo de Al Madi, et al. ${ }^{7}$, leituras espectrofotométricas e tiras de glicose foram usadas para confirmar que a presença de uma lacuna entre o núcleo e a guta-percha (GP) residual provoca significativamente mais microinfiltração do que nenhuma lacuna ao longo do tempo, ainda que haja presença de cimento entre eles. Quanto ao tipo de material cimentante, não houve diferença estatisticamente significativa quanto à microinfiltração. Entretanto, esse resultado é divergente de resultados de estudos anteriores, que indicaram que o cimento resinoso obteve um desempenho melhor que o cimento fosfato de zinco. Também foi pesquisada a hipótese de preencher essa lacuna com GP termoplastificada e foi verificado que isso reduziria a microinfiltração. Portanto, durante a preparação do dente para receber o núcleo, quantidades menores de GP residual poderiam ser mantidas, em casos de dentes com coroa-raiz curtas, compensadas com adições de GP termoplástico, a fim de obter uma melhor vedação.

Apesar de manejar os testes por meio de dois métodos de avaliação, ambos apresentaram concentrações de glicose semelhantes com correlação significativa e, com o avanço do tempo, maior presença de vazamentos. Porém, as leituras verdadeiramente se aproximaram no vigésimo dia, uma vez que inicialmente as leituras espectrofotométricas sinalizaram diferenças de infiltração entre os dias 1 e 8 , enquanto as tiras de medição de glicose mostraram essa diferença entre os dias 8 e 14. Por isso, é provável que as tiras não sejam capazes de detectar determinada concentração de glicose a princípio e, de maneira alternativa, pode-se avaliar infiltração posteriormente, para atingir maior relevância ${ }^{7}$.

A revisão de literatura elaborada por Labrada \& Cerón ${ }^{6}$ aponta dois momentos críticos para contaminação dos canais radiculares: durante o tratamento endodôntico e após o mesmo, referindo-se ao tempo até a colocação de uma restauração definitiva e à qualidade do selamento da mesma. Uma restauração temporária inadequada pode resultar em necessidades de retratamentos. Para evitar isso, além de manter o material provisório por tempo apropriado no dente e garantir o melhor selamento coronal possível, o uso de sistemas adesivos proporcionam maior sobrevida. É importante levar em consideração a necessidade de se colocar um núcleo no dente após a obturação endodôntica, uma vez que a desobstrução desses canais pode favorecer a microinfiltração bacteriana através de lacunas criadas na obturação pelo movimento e vibração dos instrumentos rotatórios. Se deixada quantidade insuficiente de guta-percha residual, pode haver comprometimento do selamento apical, favorecendo as periapicopatias. A adaptação do núcleo ao dente é mais relevante que o cimento utilizado, portanto deve ser cautelosa. Durante a preparação do espaço para 
recebimento do núcleo, os mesmos medicamentos usados durante o tratamento endodôntico podem ser usados para limpeza e desinfecção da região trabalhada. Independentemente do tipo de restauração definitiva a ser feita após o tratamento endodôntico, o tempo de permanência da restauração provisória deve ser observado e respeitado e ambos devem ser capazes de proporcionar um selamento periférico ideal, a fim de se evitar a microinfiltração bacteriana.

A revisão sistemática de Jafari, et $a l .{ }^{14}$ aborda diversos pontos sobre a microinfiltração coronal observados na literatura. O primeiro deles diz respeito aos métodos de avaliação in vitro que utilizam corantes, para os quais afirma-se que o corte longitudinal é desvantajoso em relação ao corte transversal, uma vez que as secções dificilmente passariam pelo ponto de penetração mais profunda do corante, também sendo capazes de ocasionar infiltrações. Os estudos in vitro usados para constituir essa revisão fizeram uso do corte longitudinal, exceto pela pesquisa de Al Madi, et al. ${ }^{7}$ que, por usar o modelo de filtração de glicose, não seccionou os dentes. Esse modelo é clinicamente relevante, uma vez que tal substância é um nutriente para as bactérias, resultando em colonização nos canais radiculares, por apresentar peso molecular baixo e ausência de compostos reativos. Portanto, a glicose é um bom método para avaliação da microinfiltração, apesar de demandar um longo tempo para conclusão do experimento e de reduzir a precisão dos resultados por não ter ionização para espectrometria de massa apropriada. Por outro lado, demais estudos utilizaram corantes diversos para analisar a microinfiltração, como o azul de metileno ${ }^{15}$, nitrato de prata ${ }^{8}$ e fucsina básica ${ }^{4}$, que apresentam peso molecular reduzido em comparação ao das bactérias. No entanto, o tamanho das moléculas pode ser indiferente nos resultados de vazamento. A principal limitação desse estudo é a possibilidade de não apresentar boa correlação com circunstâncias in vivo. A falta de padronização técnica é um fator que pode provocar resultados distintos, ainda que seja usada uma mesma metodologia com mínimas modificações.

Os artigos abordados nesta revisão de literatura sugerem estudos adicionais, objetivando padronizar as metodologias e consequentemente obter resultados mais fiéis e testes envolvendo outros materiais. O estudo de Babu, et al. ${ }^{4}$ ainda sugere que novas pesquisas sejam feitas voltadas para dentes decíduos. Al Madi, et al. ${ }^{7}$ por sua vez, também sugestiona, a partir de seu estudo, que a concentração de glicose usada em sua metodologia ( 2 a 2,5 mmol/L) seja pesquisada, a fim de saber se é de relevância clínica, uma vez que não foi percebida pelas tiras de glicose inicialmente. 
Esta revisão apresentou como limitações o fato de a busca por literaturas ter sido unicamente realizada através da plataforma da Biblioteca Virtual em Saúde e usadas apenas duas bases de dados, MEDLINE e LILACS. Além disso, os trabalhos utilizados nessa revisão eram constituídos de metodologias distintas, o que pode comprometer a fidedignidade dos resultados. Dessa maneira, sugere-se uma busca por artigos em outras fontes de dados e o estabelecimento de uma padronização dos estudos.

Todavia, ainda que haja as barreiras já mencionadas, este estudo possui relevância, haja vista que mostra resultados entre comparações de diferentes tipos de materiais (restauradores provisórios e permanentes e agentes cimentantes/núcleo).

\section{CONCLUSÃO}

Com base nos estudos abordados nesta revisão literária, é possível inferir que a ausência ou falha do vedamento coronário causa grandes impactos em dentes tratados endodonticamente, permitindo a infiltração microbiana nas estruturas periapicais e comprometendo o sucesso do tratamento dentário. Portanto, é fundamental o tratamento restaurador adequado e de qualidade, tanto com materiais provisórios, quanto definitivos, para que assim possam fornecer longevidade aos tratamentos endodônticos. Além disso, é necessário salientar a importância de estudos posteriores, já que há reduzidas publicações sobre o tema na literatura.

\section{REFERÊNCIAS}

1 KHADEMI, A.; SHEKARCHIZADE, N. Evaluation of coronal microleakage of mineral trioxide aggregate plug-in teeth with short roots prepared for post placement using bacterial penetration technique. Indian Journal of Dental Research, v. 27, n. 3, p. 295-299, 2016.

2 TRONSTAD, L. et al. Influence of coronal restorations on the periapical health of endodontically treated teeth. Endod Dent Traumatol, v. 16, p. 218-221, 2000.

3 RAY, H. A.; TROPE, M. Periapical status of endodontically treated teeth in relation to the technical quality of the root filling and the coronal restoration. International

Endodontic Journal, v. 28, p. 12-18, 1995. 
4 BABU, N. S. V. et al. Comparative analysis of microleakage of temporary filling materials used for multivisit endodontic treatment sessions in primary teeth: an in vitro study. Eur Arch Paediatr Dent, v. 20, n. 6, p. 565-570, 2019.

5 KIM, S-Y. et al. Quantitative microleakage analysis of endodontic temporary filling materials using a glucose penetration model. Acta Odontol Scand, v. 73, n. 2, p. 137$143,2015$.

6 LABRADA, M. V.; CERÓN, C. X. M. Influencia de la calidad de restauración coronal en el pronóstico de dientes tratados endodónticamente. Revista Cubana de Estomatología, v. 52, n. 1, p. 47-62, 2015.

7 AL-MADI, E. M. et al. Influence of Iatrogenic Gaps, Cement Type, and Time on Microleakage of Cast Posts Using Spectrophotometer and Glucose Filtration Measurements. Int J Prosthodont, v. 31, n. 6, p. 627-633, 2018.

8 MOHAJERFAR, M. et al. Coronal Microleakage of Teeth Restored with Cast Posts and Cores Cemented with Four Different Luting Agents after Thermocycling. J Prosthodont, v. 28, n. 1, p. 332-336, 2019.

9 DAMMAN, D. et al. Coronal microleakage of restorations with or without cervical barrier in root-filled teeth. Rev Odonto Cienc, v. 27, n. 3, p. 208-212, 2012.

10 KHAYAT, A.; LEE, S-J.; TORABINEJAD, M. Human Saliva Penetration of Coronally Unsealed Obturated Root Canals. Journal of Endodontics, v. 19, n. 9, p. 458-461, set., 1993.

11 SYMANSKI, N. C. et al. Temporary restorative materials used by Brazilian Dental Schools during and after endodontic treatment. RFO, Passo Fundo, v. 18, n. 1, p. 8893, jan./abr., 2013.

12 INSTITUTE, T. J. B. Joanna Briggs Institute Reviewers' Manual: Methodology for JBI Scoping Reviews. Adelaide, Austrália: The Joanna Briggs Institute, 24f., 2015.

13 GALVÃO, T. F.; PANSANI, T. D. S. A. Principais itens para relatar Revisões sistemáticas e Meta-análises: A recomendação PRISMA. Epidemiol Serv Saúde, v. 24, n. 2, p. 335-342, 2015.

14 JAFARI, F. et al. Endodontic microleakage studies: correlation among different methods, clinical relevance, and potential laboratory errors. Minerva Stomatol, v. 66, n. 4, p. 169-177, 2017.

15 LEE, K. S. et al. In vitro microleakage of six different dental materials as intraorifice barriers in endodontically treated teeth. Dental Materials Journal, v. 34, n. 4, p. 425431, 2015. 